\author{
Military Technical College \\ Cairo, Egypt
}

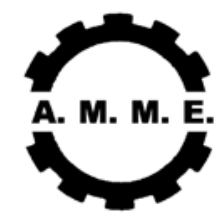
$12^{\text {th }}$ International Conference on Applied Mechanics and Mechanical Engineering (AMME)
May 16-18, 2006

\title{
BALLISTIC RESISTANCE OF FLEXIBLE COMPOSITE AND TEXTILE TARGETS
}

\author{
E. Elawad ${ }^{*}$, A. Fayed ${ }^{*}$, and M. S. Abdelkader ${ }^{* *}$
}

\begin{abstract}
Advanced textile and flexible composites always used for the containment of high-speed fragmentation. The design of body armours, fragmentation curtains and bomb blankets are end products. In this work, an experimental program is conducted to test a new composite material (3D-weaveTM Kevlar-129/ LINE-X xs-350), which is a two-component spray-in-place flexible $100 \%$ solids Polyurea/Polyurethane system. Ballistic response of this new composite is compared to that of (3D-weaveTM) Kevlar-129; the multi-layered targets of the two materials are subjected to impact by small arm projectiles with velocity range of $300-450 \mathrm{~m} / \mathrm{s}$.

Moreover, a finite element code based on Newtonian formulation is used to predict the nodal acceleration, velocity and displacement. Forces acting on both projectile and target are also predicted. A comparison between experimental results and predictions of the code showed general good agreement in the case of Kevlar targets. The agreement was not quite as good, but still acceptable, for composite targets. The average energy absorbed per one layer of the new composite and Kevlar targets is determined.

Predictions show that the composite targets are generally more efficient than the Kevlar targets in defeating impacting projectiles.

Finally, post firing examination of Kevlar/line-x targets shows recoverable behaviour and localized damage after the ballistic impact; this means small trauma effect occurred when using this composite as body armour.
\end{abstract}

* Egyptian Armed Forces.

** Prof., Arab Academy for Science, Technology and Maritime Transport. 


\section{INTRODUCTION}

Polymer textile composites resist the impact by absorbing the projectile's kinetic energy as both target material kinetic energy and strain energy when it is subjected to ballistic impact loading. The following reviews previous work in the filed of penetration of textile and composite materials.

Leech, et al [1] proposed a model for describing the arrest of high speed projectiles by orthogonally woven cloth and nets obtained using a variational principle.

Their work was based on the idea of the wave front generated by a localized impact on orthogonally woven cloth and dense nets was theoretically shown to be rhomboidal. They obtained an approximate solution for the behavior of both linear (small deflection) and non-linear (large deflection) systems.

Zhu, et al [2] studied quasi-static and dynamic penetration of cylindro-conical projectiles into composite targets consisting of woven Kevlar-29 fiber plies in a thermosetting polyester matrix curing at room temperature. In the quasi-static test, a closed loop servo hydraulic testing system using load cell with a capacity of $400 \mathrm{kN}$ was used. The penetrator consisted of hard steel cylinder having diameter of $12.7 \mathrm{~mm}$ with a conical or a blunt tip. Cone angles employed were $60^{\circ}, 90^{\circ}$, and $120^{\circ}$. The dynamic penetration tests utilized $12.7 \mathrm{~mm}$ and $9.5 \mathrm{~mm}$ diameter cylindro-conical steel projectiles with $60^{\circ}$ tip angle and mass of 28.9 and $15.4 \mathrm{~g}$, respectively.

Shim, et al [3] examined the dynamic mechanical properties of Twaron fabric via high-speed tensile tests of specimens using a split Hopkinson bar. The loaddeformation and failure characteristics at different rates of stretching were determined, from which constitutive equations representing its viscoelasticity and strain-rate dependence were formulated. These facilitated modeling of the material response to impact and perforation. Experimental results indicated that Twaron is highly strain-rate dependent; the tensile strength and modulus increase with strain rate while the failure strain decreased. Twaron specimens were also observed to fail in a more brittle fashion when the strain rate increased. This phenomenon significantly reduces the amount of energy absorbed at high strain rates.

Walker [4] examined the ballistic limit of fabric sheets with the equivalent areal density of fabric/resin composite. It was shown that for low relative areal densities of fabric, the loss in fabric material (by weight) by adding resin could lead to the loss in performance of the armor system. However, as the relative areal density increased, the fabric/resin composite panel began to show bending stiffness, and its performance increased. Experimentally, it has been observed that the cross over in performance was in the region where the mass of fabric 
material involved in the momentum balance equal to the mass of the impacting bullet. As the areal density of the fabric increases beyond this point, the ballistic resistance of fabric/resin composite panel became better than that of a dry fabric with equivalent areal density.

DeLuca, et al [5], tested different sizes of S2-glass-fabric-reinforced plastic (GFRP) laminate plates ballistically by impacting them with two different sizes of fragment simulating projectiles at various velocities below the ballistic limit. The impacted specimens were examined with computed tomography to determine the extent of damage in the specimens, and then those specimens were tested in compression until failure. Laminates were made of S2-glass woven roving in polyester resin matrix with resin content $32 \%$ by weight. All targets were made of GFRP panel $20 \times 20 \mathrm{~mm}$ in size, and were rigidly fixed. Tests were conducted with fragment simulators of mass 207 grains, $12.7 \mathrm{~mm}$ caliber, and 830 grains, $20 \mathrm{~mm}$ caliber at normal impact.

Billon and Robinson [6] presented two numerical models and an analytical model for assessing the ballistic performance of multi-layer fabrics of different types. The model predictions were compared with experimental results. Projectiles used were of caliber 5.59 and $7.62 \mathrm{~mm}$ with velocities ranging from $200-750 \mathrm{~m} / \mathrm{s}$. Tested fabrics were ballistic nylon, high modulus polyethylene (HMPE), and aramid. The models gave good agreement with the experimental results of the two types of fabrics.

Fayed and Leech [7], presented a simulation code that predicted the dynamics of flexible textile/ laminate systems due to transverse high-speed impact. The simulation code was based on finite element theory, incorporating finite strain tensors to describe the deformation, and textile/laminate constitutive equations to represent the in-plain stress-strain behavior of the system. To validate the model and to acquire performance data, various ballistic impact experiments were conducted; the impact was nominally $0.885 \mathrm{gm}$ at $500 \mathrm{~m} / \mathrm{s}$, the projectile being a $6-\mathrm{mm}$ steel ball, and the two candidate targets were flexible composite. The $\mathrm{V}_{50}$ for these two composite materials has been measured by firing through many layers, and determining the velocity loss at each impact. The model gave good agreement with the experimental results of the two composite systems.

Fayed, et al [8], studied the normal perforation of a small caliber projectile into textile /epoxy composite targets. They used a Kevlar-129 and S-2 glass textiles for manufacturing the composite which had a new weave shape (3D weave ${ }^{\mathrm{TM}}$ ). Tests were performed to determine their mechanical properties and an analytical model was presented to describe the penetration process and to evaluate their ballistic resistance against small caliber projectiles. Experimental results were compared with model predictions; good agreement was generally obtained. Results showed that the tested composites had a limited ballistic resistance. 
Fayed, et al [9], Studied experimentally the ballistic response of a new composite (3D weave ${ }^{T M}$ Kevlar-129 fabric and Line-x (xs 350 type) polymer. Ballistic response of this new composite was compared to that of (3D-weaveTM) Kevlar129; the multi-layered targets of the two materials were subjected to impact by small arm projectiles in the velocity range of $300-450 \mathrm{~m} / \mathrm{s}$. The average energy absorbed per one layer of the new composite and Kevlar targets was calculated. Calculations show that the composite targets are generally more efficient than the Kevlar targets in defeating impacting projectiles.

The present work encompasses the following main objectives:

- To enhance the experimental study of the ballistic resistance of multi-layer (3D weave ${ }^{T M}$ ) Kevlar-129 fabric and a flexible composite target using LINE-X (xs 350 type) impacted with $7.62 \mathrm{~mm}$ projectile with different impact velocities, thus showing the effect of projectile impact velocity and number of layers on the ballistic resistance of composite and comparing the energy absorption in the two systems, which is made in [9].

- To construct a penetration model, based on analytical models of other investigators, capable of describing the penetration process of the Kevlar 129 fabric targets and the composite targets, and presents its general structures and main equations. Within the realm of this objective, a computer program to solve the penetration problem will be coded.

- To analyse the results obtained from the ballistic test for the Kevlar and composite targets.

- To compare the experimental firing velocities with the predicted by the model.

\section{EXPERIMENTAL WORK}

In general, the scheme of the experimental work performed in this study included the following phases: i) Target material choice and preparation, ii) Material characterization, iii) Ballistic tests and measurements and, iv) Post-firing examinations.

\subsection{Target Material Choice and Preparation}

The polymeric composite used in this study consisted of Polyurea/Polyurethane P.P. polymer, reinforced by (3D weave ${ }^{\mathrm{TM}}$ ) Kevlar-129 textile. It was chosen because it had high energy absorption during failure, which made it ideal for ballistic protection. It also had low density, high strength-to-weight ratio, and high modulus-to-weight ratios.

LINE-X XS-350 was a two-component spray-in-place flexible $100 \%$ solids Polyurea/Polyurethane system. It was designed for processing through LINE-X dispensing equipment. It was fast-set and fast-cure material. It also exhibited excellent adhesion to most materials including steel, concrete, wood, fiber glass, 
and Kevlar. LINE-X was suitable as a protective abrasive impact liner for pipelines, tanks, industrial floors, sea water vessels, helicopter decks, and proved for blast mitigation. Table (1) lists the mechanical properties of the LINEXXS-350.

Table (1) Mechanical properties of LINE-X XS-350.

\begin{tabular}{|c|c|}
\hline Properties at $24^{\circ} \mathrm{C}$ & Value \\
\hline Density $\left[\mathrm{gm} / \mathrm{cm}^{3}\right]$ & 1.123 \\
\hline Hardness,(shore A/shore D) & $87 / 60$ \\
\hline Tensile strength [MPa] & 20.4 \\
\hline Shear strength [MPa] & 21.94 \\
\hline Elongation, [\%] & 475 \\
\hline
\end{tabular}

In this study LINE-X was tested for improving the ballistic resistance of Kevlar textile. It had high resistance to sun ultra violet radiation and severe weather conditions. It also had low density and outstanding abrasion resistance, impact strength, tensile strength, tear strength and high elongation percent. The preparation and mechanical testing of this new composite was published in [9].

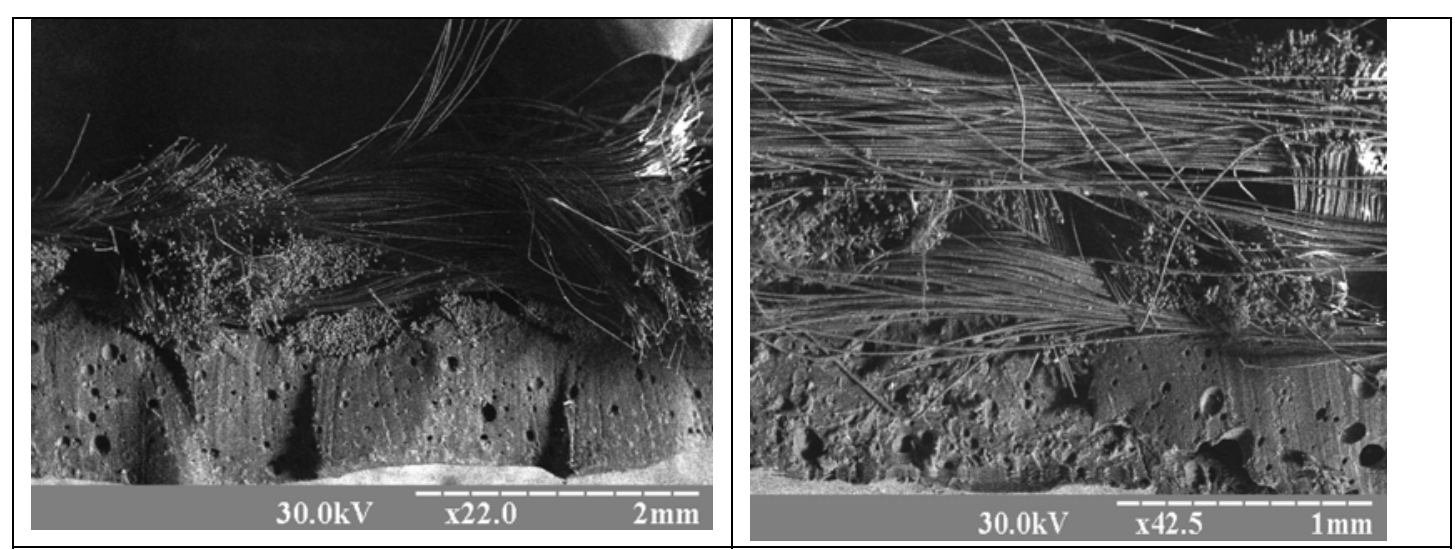

Fig. (1) Microscopic photography of produced composite.

\subsection{Ballistic Tests and Measurements}

In the ballistic tests performed, measurements were mainly concerned with the determination of the projectile impact and post-perforation velocities for different targets at different firing conditions. The problem of velocity measurement was actually converted to the measurement of time at which the projectile took to pass over a fixed distance. This gave an average value of the velocity. Arrival and departure of projectile over predetermined distances could be detected by the breaking or connecting of electric circuits, to start and stop a time counter. Both ballistic set up and material characterization were mentioned also in [9]. 


\subsection{BALLISTIC FIRING TEST RESULTS}

\section{Determination of Projectile impact and residual velocities}

The impact velocity was controlled by changing the mass of propellant charge. A set of projectiles with different propellant charges was fired against each target. The projectiles impact and residual velocities were measured using the velocity measuring system that has mentioned in [9].

\section{Results of Kevlar Targets}

\section{Effect of projectile impact velocity}

Figure (2) illustrates the change of the residual velocity $v_{r}$ with the impact velocity $v_{i}$. Best regression lines were used to fit the results. For each target, the figure shows that the residual velocity increases with the increase of impact velocity in a quasi-linear manner over the used range of velocity. Similar results were obtained by Resnyansky and Kataselis [10]; they fired ball projectiles on carbon fiber targets of thickness 1.5, 3, 4.5 and $6 \mathrm{~mm}$ in the velocity range from $280 \mathrm{~m} / \mathrm{s}$ up to $970 \mathrm{~m} / \mathrm{s}$.

The change of the velocity drop, $\Delta v=v_{i}-v_{r}$, with the impact velocity is represented in Fig. (3). It can be seen from the figure that the velocity drop decreases continuously by the increase of the projectile impact velocity for each target. This trend was maintained at all impact velocities considered, indicating that no change in the failure mechanism is likely to have taken place.

The relation between the projectile impact energy $E_{i}$ and the projectile residual energy $E_{r}$ is represented in Fig. (4). It is found that for each target the residual projectile energy increases by the increase of the impact energy.

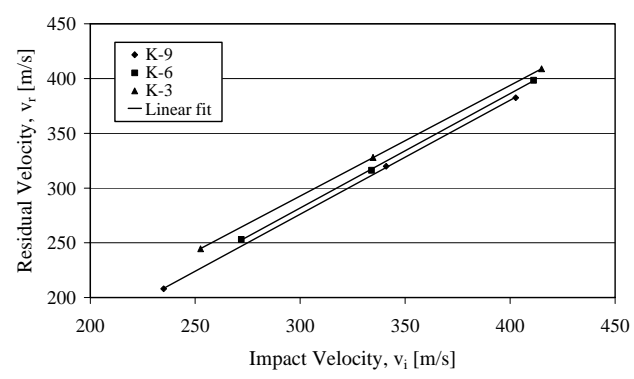

Fig. (2) Measured residual velocity versus impact velocity for Kevlar targets with different number of layers.

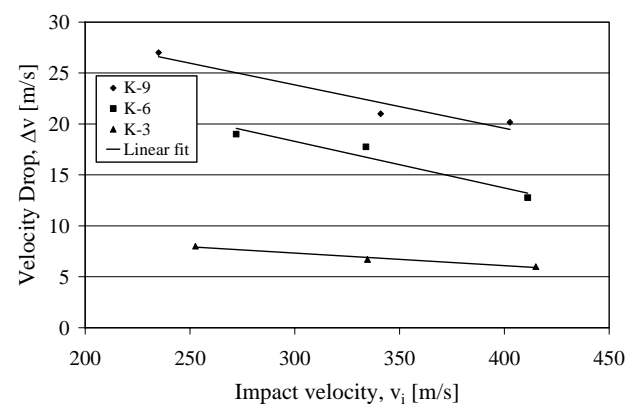

Fig. (3) Projectile velocity drop versus impact velocity for Kevlar targets with different number of layers . 


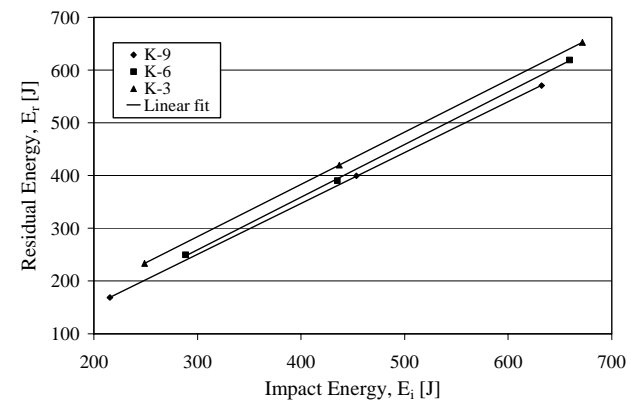

Fig. (4) Change of projectile residual energy with impact energy for Kevlar targets with different number of layers.

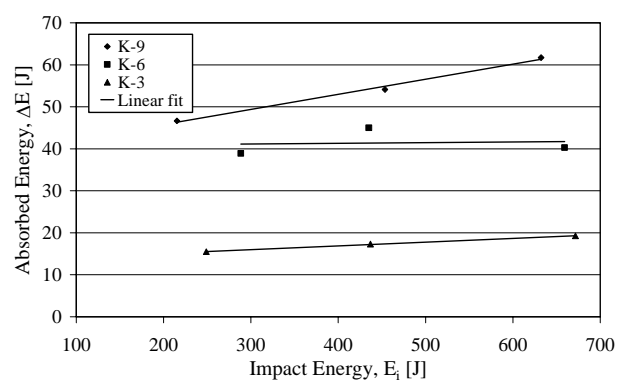

Fig. (5) Change of target absorbed energy with projectile impact energy for Kevlar targets with different number of layers.

The energy absorbed during the target penetration $\Delta \mathrm{E}$ was calculated as the difference between the projectile impact and residual energies. Figure (5) represents the change of the energy absorbed by the target with the projectile impact energy. The figure shows that the energy absorbed by each target increases with the increase of the impact energy. These results are in agreement with those of Fayed $[7,8]$.

\section{Effect of number of layers}

In the following, the ballistic resistance of the tested Kevlar 129 targets is evaluated through studying the effect of number of layers on the velocity drop $\Delta v$, the absorbed energy by the target $\Delta \mathrm{E}$.

Figure (6) depicts the change of the velocity drop with the target number of layers at the impact velocities $v_{i}=253$ and $408 \mathrm{~m} / \mathrm{s}$. The figure shows that the velocity drop increases by increasing the number of layers.

The effect of number of layers on the energy absorbed is shown in Fig. (7)It can be seen that the energy absorbed by the target increases by adding more Kevlar layers to the target. Dividing the energy absorbed by the target by the number of target layers, one gets the average energy absorbed by one layer and also for every target type, the absorbed energy per one composite layer is almost twice that absorbed per one Kevlar layer, as shown in fig. (7).

It is clear that this "specific" energy also increases with number of layers, a result which has been obtained by many investigators for almost all types of targets, e. g. $[11,12]$. 


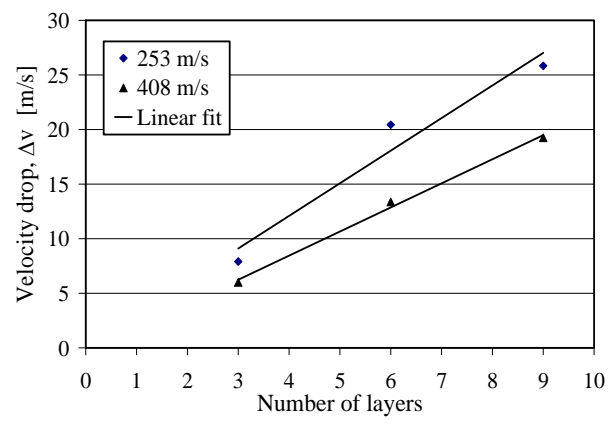

Fig. (6) Projectile velocity drop versus Kevlar target number of layers at $v_{i}=253$ and $408 \mathrm{~m} / \mathrm{s}$.

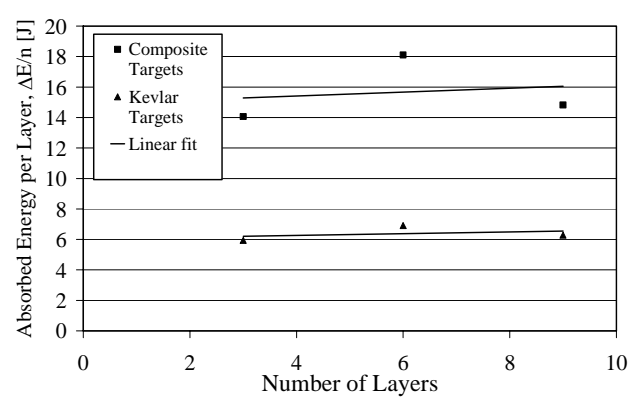

Fig. (7) Energy absorbed by Kevlar and Composite targets versus target number of layers.

\section{Results of Composite Kevlar/LINE-X Target. Effect of projectile impact velocity.}

The same parameters chosen to evaluate the ballistic resistance of the $\mathrm{K} / \mathrm{L}$ composite targets are the same as those used in the preceding section. Fig. (8) presents the relation between the residual velocity $v_{r}$ and the impact velocity $v_{i}$. This relation is in general similar to that of the Kevlar targets; the residual velocity increases with the increase of impact velocity.

The relation between the velocity drop and the impact velocity during penetration is shown in Fig. (9). It is seen that the velocity drop during penetration decreases as the impact velocity increases. In Fig.(10) the residual energy $E_{r}$ increases by the increase of the impact energy, which is similar to the behavior of the Kevlar targets. In Fig.(11), however, the energy absorbed $\Delta \mathrm{E}$ behaves in a different manner. It increases by the increase of the impact energy $E_{i}$.

From the previous relations it can be seen that the composite behaves qualitatively like the Kevlar fabric in resisting the projectiles. Based on this similarity, one can anticipate that the failure modes of the Kevlar/LINE-X composite and the Kevlar fabric are most likely the same. This is probably because the Kevlar fabric is the effective constituent of the composite in ballistic resistance.The obtained results agree with that of Bohong Gu [13], who tested two kinds of multi-layered plain fabric targets made of Twaron and Kuralon fibers. 


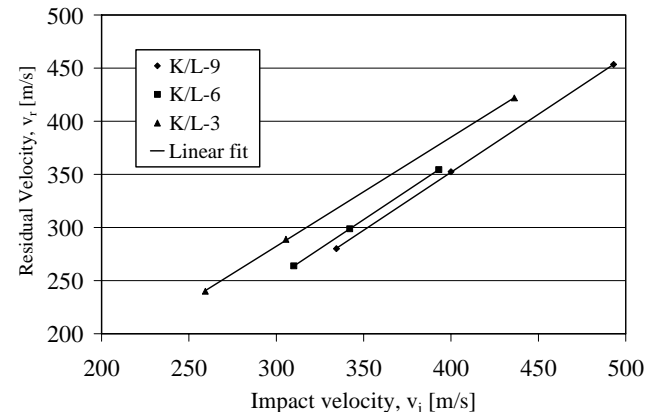

Fig. (8) Measured residual velocity versus impact velocity for different number of layers of composite targets.

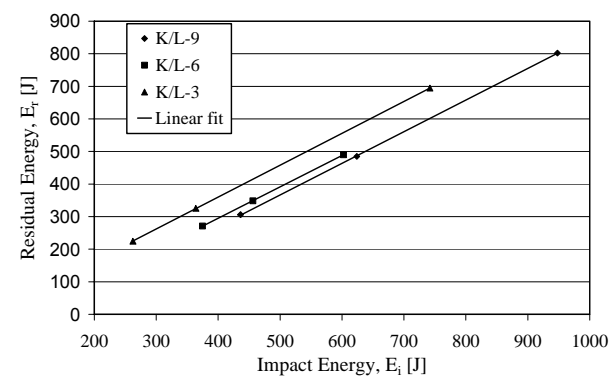

Fig. (10) Change of projectile residual energy with impact energy for different number of layers of composite targets.

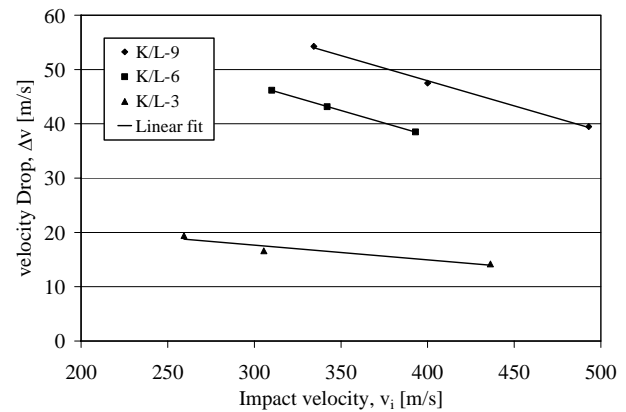

Fig. (9) Projectile velocity drop versus impact velocity for different number of layers of composite targets.

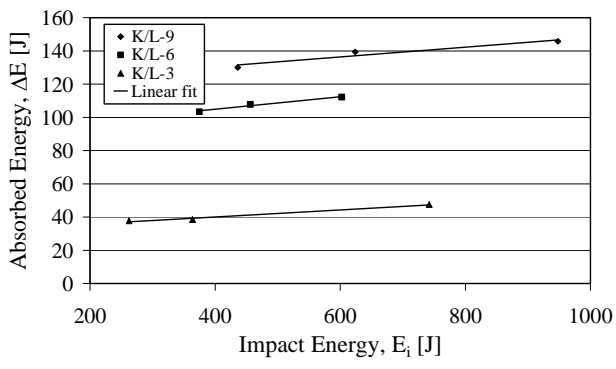

Fig. (11) Change of energy absorbed by target with projectile impact energy for different number of layers of composite targets.

\section{Effect of number of layers}

The ballistic resistance of the composite targets is evaluated by studying the effect of increasing the number of layers on the velocity drop $\Delta v$, and absorbed energy $\Delta \mathrm{E}$. Two impact velocities were selected for this study, $323 \mathrm{~m} / \mathrm{s}$ and 414 $\mathrm{m} / \mathrm{s}$. The velocity drop increases by the increase of number of layer for both impact velocities. This result is described in Fig. (12). Fig. (13) Shows the energy absorbed by the target as it changes with the number of layers. Also, the absorbed energy increases by adding more layers of the used composite.

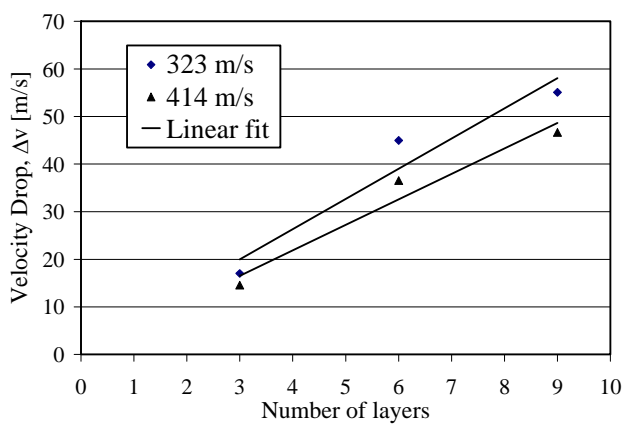

Fig. (12) Projectile velocity drop versus composite target number of layers at $v_{i}=323$ and $414 \mathrm{~m} / \mathrm{s}$.

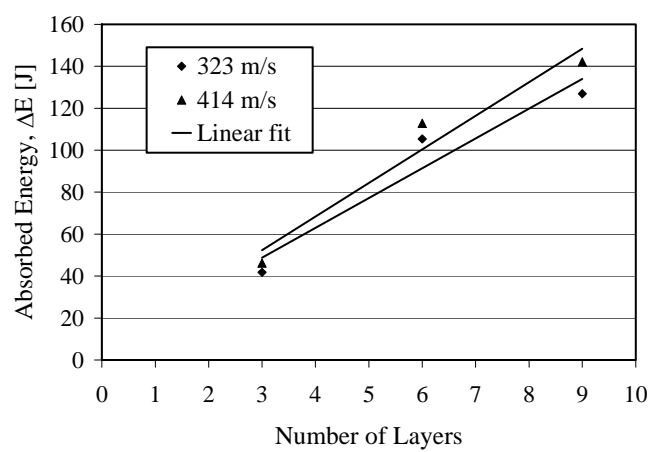

Fig. (13) Target absorbed energy versus composite target number of layers at $v_{i}=323$ and $414 \mathrm{~m} / \mathrm{s}$. 


\section{ANALYTICAL MODEL}

The present model was based on the work of Roylance and Wang [14]. They modelled the fabric as an assembly of nodes interconnected by flexible fiber elements, forming an orthogonal mesh. Each element was assigned the mechanical properties of the yarns. Initially, point load on a single node was used to simulate projectile loading. The static properties of the fabric were used in their analysis. As a modification, this model was tested in simulation of the mentioned new composite with some modification as will see here in.

\subsection{Method of Analysis and Assumptions}

1. Woven panel is idealized as an assemblage of pin-jointed flexible fiber elements in an orthogonal mesh; each element has a mass which makes the areal density of the idealized mesh equal to that of the woven panel.

2. Nodes are defined by cross-over point of orthogonal fabric yarns.

3. Mass of the elements is lumped on the nodes.

4. The mass of projectile is added to the nodes involved in the impact area.

5. The number of layers is simulated by multiplying the mass of one layer by the number of layers.

6. Each node can only move in the direction of the projectile motion.

7. Initial projectile velocity is imposed on the node at the impact point, which causes a strain to develop in the adjacent elements.

8. The tension in each element can be calculated from the strain by applying the constitutive relation of the material.

9. From the inclination of the element, the force applied on the projectile is the component of the tension in the direction of the motion. This force is used to calculate deceleration of the projectile and the acceleration of the other adjacent nodes.

10. Using momentum-impulse balance, strain-displacement conditions, and constitutive relation, values of tension, strain, velocity, and displacement, are computed for each element.

11. The process is repeated for another time increment until projectile stops, or penetration of target occurs.

\subsection{Mathematical Formulation}

The impulse momentum balance during the time $\mathrm{dt}$ can be written as

$$
\Delta \mathrm{m} . \mathrm{dv}=\mathrm{T} . \mathrm{dt}
$$

Where $d v$ is the incremental velocity, $T$ is the resultant tensile force (on the element), and $\Delta \mathrm{m}$ is lumped mass of the fabric at the node.

The resultant force on a node $(\mathrm{i}, \mathrm{j})$ in the direction of projectile motion is given by:

$$
\Sigma F_{i, j}=T_{(i, j) x} \sin \theta_{(i, j) x}+T_{(i, j) y} \sin \theta_{(i, j) y}+T_{(i-1, j) x} \sin \theta_{(i-1, j) x}+T_{(i, j-1) y} \sin \theta_{(i, j-1) y} \text {, }
$$

where $T$ is the force in the element, $(i, j)$ are the $x$ and $y$ coordinates of the node, and $\theta$ is the angle between the direction of the force $T$ and the plane of the cloth. 
The resultant force is perpendicular to the cloth. This force gives the out-of-plane acceleration of each node.

$$
\Sigma \mathrm{F}=\Delta \mathrm{m} \cdot \mathrm{a}_{\mathrm{i}, \mathrm{j}}
$$

The force in the element is given by:

$$
\mathrm{T}=\mathrm{E} . \mathrm{A} . \varepsilon,
$$

where $E$ is Young's modulus, $A$ is cross-sectional area of the element, and $\varepsilon$ is the strain in the element

The strain is given by:

$$
\varepsilon=\frac{\sqrt{\mathrm{dx}^{2}+\mathrm{dw}^{2}}-\mathrm{dx}}{\mathrm{dx}}=\sqrt{1+\left(\frac{\mathrm{dw}}{\mathrm{dx}}\right)^{2}}-1,
$$

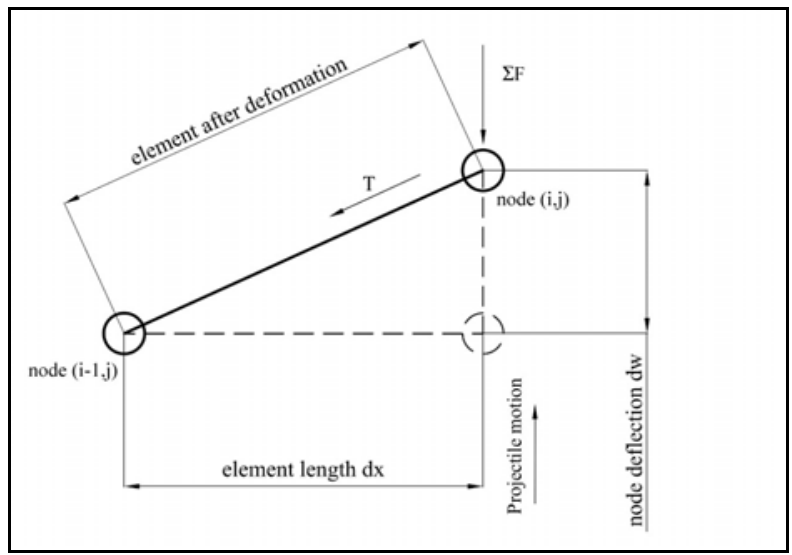

Fig. 14 Deflection generated due to node motion in the direction of projectile motion

where $d x$ is the length of the element, $d w$ is the difference in the displacement (out-of-plane) of the two nodes of the element as shown in Fig. (14).

The impulse momentum balance equation (1) and the equation of motion can be written numerically as:

$$
\begin{aligned}
& \frac{\Delta \mathrm{m}\left(\mathrm{v}_{\mathrm{t}+1}-\mathrm{v}_{\mathrm{t}}\right)}{\mathrm{dt}}=\frac{\mathrm{T}_{\mathrm{t}+1}+\mathrm{T}_{\mathrm{t}}}{2} \\
& \frac{\mathrm{w}_{\mathrm{t}+1}-\mathrm{w}_{\mathrm{t}}}{\mathrm{dt}}=\frac{\mathrm{v}_{\mathrm{t}+1}+\mathrm{v}_{\mathrm{t}}}{2}
\end{aligned}
$$

The main equations representing the present model are arranged and compiled into a computer program. The flow chart of the constructed program is described in Fig. (15) 


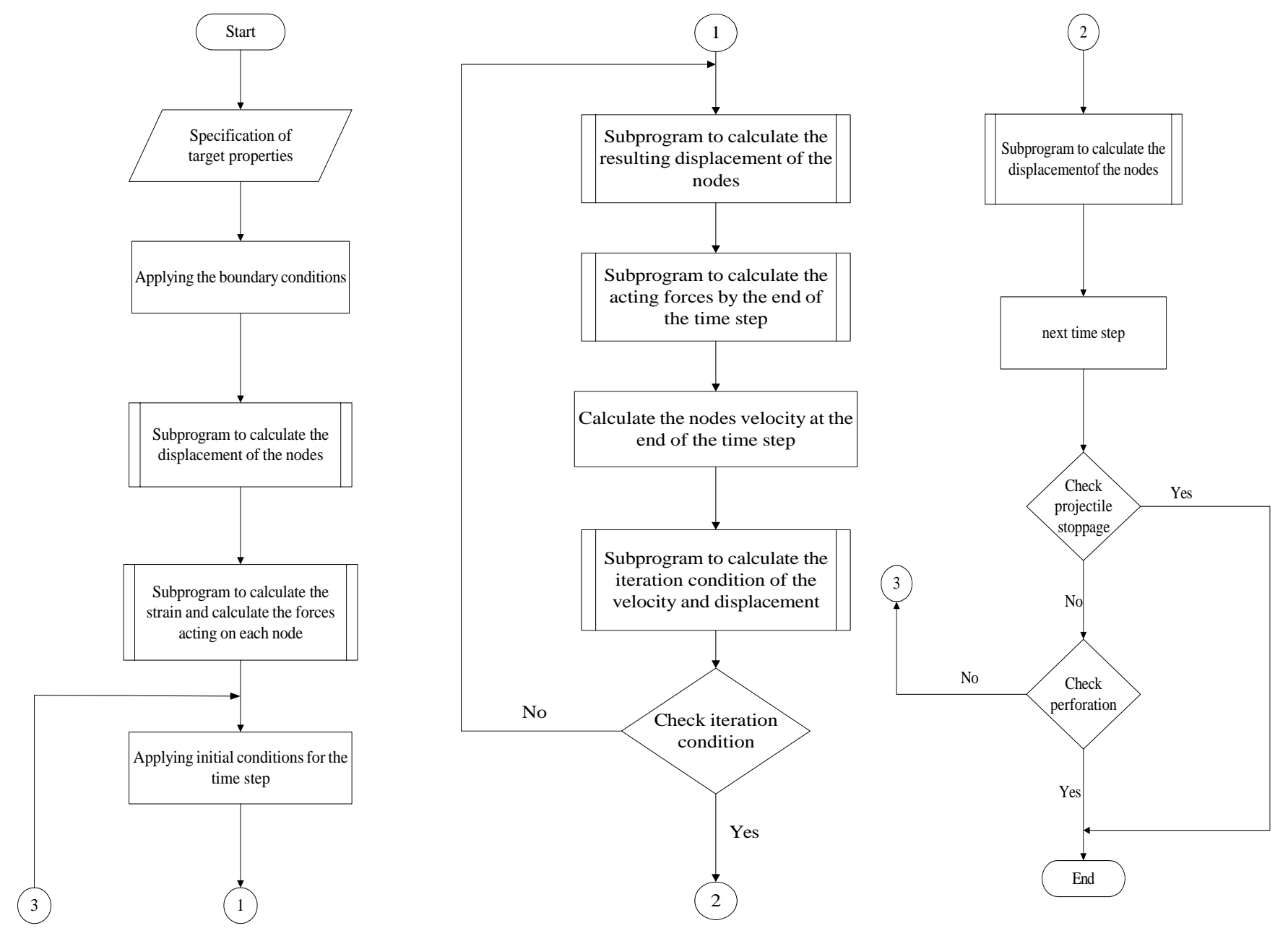

Fig. 15 Flowchart showing the procedures of solution for the fabric

\subsection{Sample Results}

\section{Input data}

The input data to the model presented in this work depended mainly on the tensile failure of the tested targets. For describing the penetration of the projectile into Kevlar target, the input data are: projectile mass is $7.8 \mathrm{~g}$, Kevlar 129 fiber modulus of elasticity is $99 \mathrm{GPa}$, the ultimate strain of the Kevlar fiber is 0.044 , the density of Kevlar 129 is $1.44 \times 10^{3} \mathrm{~kg} / \mathrm{m}^{3}$, the areal density of the Kevlar 129 target is equal to the number of layers multiplied by $0.6411 \mathrm{~kg} / \mathrm{m}^{2}$, and the time step of the calculations is $5 \mu \mathrm{s}$.

In the case of describing the penetration of the projectile into the composite target, the input data are: projectile mass is $7.8 \mathrm{~g}$, composite modulus of elestisity is $4.617 \mathrm{GPa}$, the ultimate strain of the composite material is 0.14 , the density of the composite is $1.233 \times 10^{3} \mathrm{~kg} / \mathrm{m}^{3}$, the areal density of the composite 
target is equal to the number of layers multiplied by $1.6214 \mathrm{~kg} / \mathrm{m}^{2}$, and the time step of the calculations is $5 \mu \mathrm{s}$.

\section{Projectile mass distribution}

The projectile mass is distributed at the nodes laid in the projectile projected area. In case of an element length of $1.6 \mathrm{~mm}$, Fig.(16), the whole nodes laid in the projectile projected area were shown. Figures (17), (18) and (19) illustrate the nodes laid in the projectile projected area in cases of an element size of $0.8,0.4$ and $0.2 \mathrm{~mm}$, respectively. Because of symmetry, the figures show only a quarter of the target and projectile. The number of nodes under the projectile for each element size is listed in Table (2).

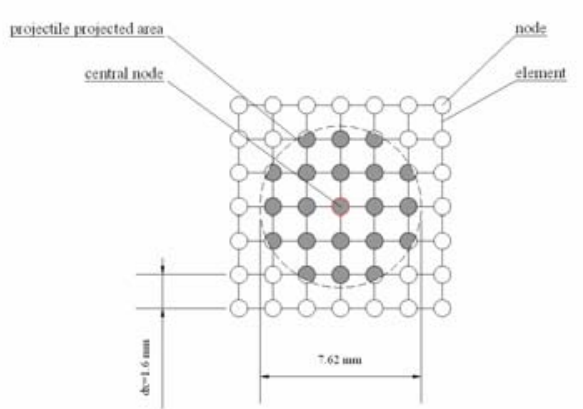

Fig. (16) Projectile mass distribution for $\mathrm{dx}=1.6 \mathrm{~mm}$

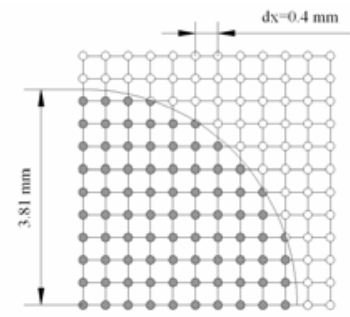

Fig. (18) Projectile mass distribution for $\mathrm{dx}=0.4 \mathrm{~mm}$

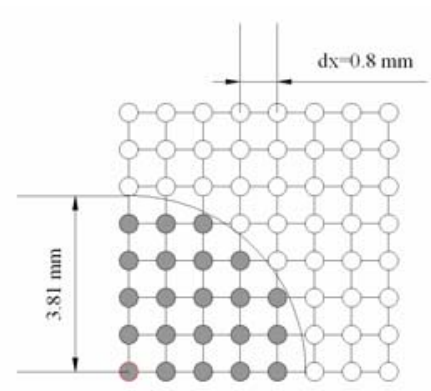

Fig. (17) Projectile mass distribution for $\mathrm{dx}=0.8 \mathrm{~mm}$

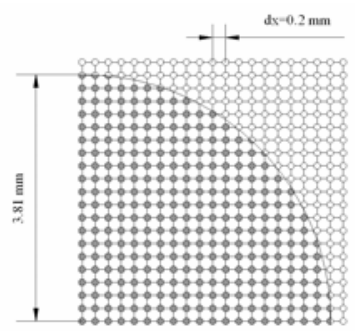

Fig. (19) Projectile mass distribution for $\mathrm{dx}=0.2 \mathrm{~mm}$

Table (2) Number of nodes in the projectile projected area

\begin{tabular}{|c||c|}
\hline Element size, dx [mm] & Number of nodes \\
\hline \hline 1.6 & 21 \\
\hline 0.8 & 69 \\
\hline 0.4 & 293 \\
\hline 0.2 & 1137 \\
\hline \hline
\end{tabular}

\section{Element size}

Element size affects the predicted residual velocity considerably. In general, this effect decreases by decreasing the element size and converges eventually to a certain response. The change of element size consequently changes the projectile mass distribution. Table(3) lists the predicted ballistic limit for each tested target for different element sizes. This table shows a maximum relative difference of $9.3 \%$ for K/L-6. 
Based on this result the element size $d x=0.2 \mathrm{~mm}$ will be used in further predictions of the model. To further investigate the predictive capabilities of the model its output is compared to both experimental and numerical results of other investigators. For instance, Fig. (20) Depicts experimental as well as predicted residual velocity change with impact velocity for 9-layer Kevlar 129/epoxy target [8], predictions being obtained using the current model are also plotted on the same figures. It is clear that the three responses are in fairly good agreement.

Table (3) Effect of element size on the predicted

ballistic limit for tested targets

\begin{tabular}{|c||c|c||c|c|c||}
\hline \multirow{2}{*}{$\begin{array}{c}\text { Targe } \\
\mathrm{t}\end{array}$} & \multicolumn{5}{|c|}{ Predicted ballistic limit [m/s] } \\
\cline { 2 - 6 } & $\begin{array}{c}\mathrm{dx}=1 . \\
6 \mathrm{~mm}\end{array}$ & $\begin{array}{c}\mathrm{dx}=0 . \\
8 \mathrm{~mm}\end{array}$ & $\begin{array}{c}\mathrm{dx}=0.4 \\
\mathrm{~mm}\end{array}$ & $\begin{array}{c}\mathrm{dx}=0.2 \\
\mathrm{~mm}\end{array}$ & $\begin{array}{c}\mathrm{dx}=0.1 \\
\mathrm{~mm}\end{array}$ \\
\hline \hline $\mathrm{K}-9$ & 112 & 102 & 105 & 104 & 104 \\
\hline \hline $\mathrm{K}-6$ & 92 & 84 & 86 & 85 & 85 \\
\hline \hline $\mathrm{K}-3$ & 65 & 59 & 61 & 60 & 60 \\
\hline \hline $\mathrm{K} / \mathrm{L}-9$ & 129 & 118 & 121 & 119 & 120 \\
\hline \hline $\mathrm{K} / \mathrm{L}-6$ & 107 & 97 & 100 & 99 & 99 \\
\hline \hline $\mathrm{K} / \mathrm{L}-3$ & 77 & 70 & 72 & 71 & 71 \\
\hline
\end{tabular}

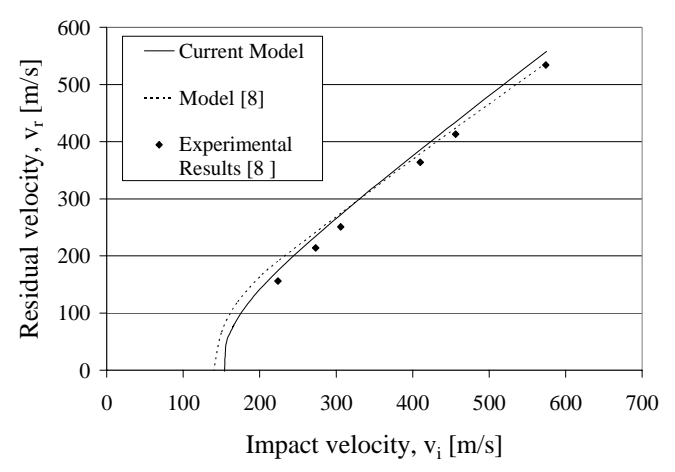

Fig. (20) Comparison the predictions of the current model to the results of [8]

\section{Comparison between predicted and measured results for Kevlar targets}

The values of the measured and predicted residual velocities for Kevlar targets are listed in Table (4). The table also lists the relative difference of residual velocities. From the table, the maximum value of the relative difference is $2.96 \%$ and is encountered in case of the K-6 target at $v_{i}=272 \mathrm{~m} / \mathrm{s}$

Figures (21), (22), and (23) show the difference between the predicted and measured residual velocities for the targets K-3, K-6, and K-9, respectively. The predicted results gave good agreement with the experimental results especially in case of three-layer target.

The consistence between predicted and experimental results validates the assumptions of the analytical model. The relative difference increases with the increase of the number of layers. This may be due to the adding more layers which gives the fiber somehow bending stiffness and increases its ballistic resistance.

These results give us the advantage to predict the ballistic limit of the tested targets which are for the target K-3 $\mathrm{V}_{\mathrm{lim}}=70 \mathrm{~m} / \mathrm{s}$, for the target K-6 $\mathrm{V}_{\mathrm{lim}}=100 \mathrm{~m} / \mathrm{s}$, and for the target K-9 $\mathrm{V}_{\mathrm{lim}}=122 \mathrm{~m} / \mathrm{s}$.

Table (4) Measured and predicted residual velocities and their relative difference for Kevlar targets. 


\begin{tabular}{|c|c|c|c|c|}
\hline \multirow[t]{2}{*}{ Target } & \multirow{2}{*}{$\begin{array}{l}\text { Impact } \\
\text { velocity } \\
v_{\mathrm{i}}[\mathrm{m} / \mathrm{s}]\end{array}$} & \multicolumn{2}{|c|}{$\begin{array}{l}\text { Residual velocity } v_{\mathrm{r}} \\
{[\mathrm{m} / \mathrm{s}]}\end{array}$} & \multirow{2}{*}{$\begin{array}{c}\text { Relative } \\
\text { difference } \\
{[\%]}\end{array}$} \\
\hline & & Measured & Predicted & \\
\hline \multirow{3}{*}{ K-9 } & 235 & 208 & 214 & 2.88 \\
\hline & 341 & 320 & 327.3 & 2.28 \\
\hline & 402 & 382 & 389.6 & 1.99 \\
\hline \multirow{3}{*}{ K-6 } & 272 & 253 & 260.5 & 2.96 \\
\hline & 334 & 316.25 & 324.3 & 2.55 \\
\hline & 411 & 398.4 & 403 & 1.15 \\
\hline \multirow{3}{*}{ K-3 } & 252.6 & 244 & 246.5 & 1.02 \\
\hline & 334 & 328 & 329 & 0.304 \\
\hline & 415 & 409 & 411.4 & 0.586 \\
\hline
\end{tabular}

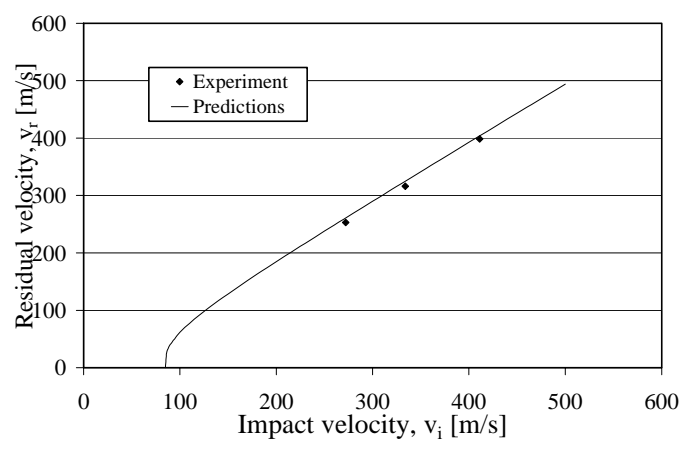

Fig. (22) Comparison between predicted and measured residual velocities for K-6 targets

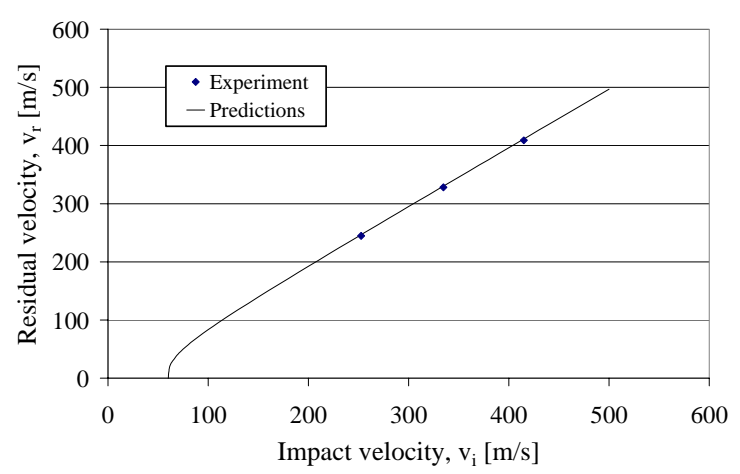

Fig. (21) Comparison between predicted and measured residual velocities for K-3 targets

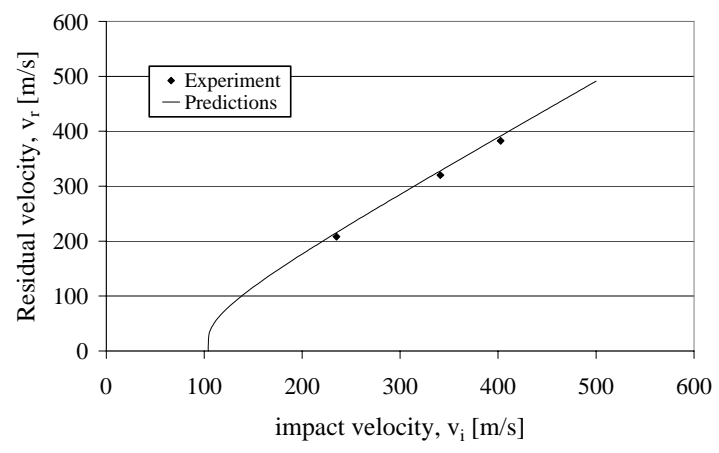

Fig. (23) Comparison between predicted and measured residual velocities for K-9 targets

\section{Comparison between predicted and measured results for composite targets}

The values of the measured and predicted residual velocities for composite targets are listed in Table (5). The table also lists the relative difference of residual velocities. From the table, the maximum value of the relative difference is $12.39 \%$ and is encountered in case of the $\mathrm{K} / \mathrm{L}-6$ targets at $\mathrm{v}_{\mathrm{i}}=310 \mathrm{~m} / \mathrm{s}$.

Fig. (24), (25), and (26) show the difference between the predicted and measured residual velocities for the targets $\mathrm{K} / \mathrm{L}-3, \mathrm{~K} / \mathrm{L}-6$, and $\mathrm{K} / \mathrm{L}-9$, respectively. The predicted results give good agreement with the experimental results. The difference between measured and predicted results increases as the number of layers increase. This difference may be due to adding the LINE-X layer which allows more fibers in the fabric to resist the projectile. It is also possible that the LINE-X layer gives the fiber bending stiffness, which is not considered in the model.

Table (5) Measured and predicted residual velocities and their relative difference for composite targets. 


\begin{tabular}{|c|c|c|c|c|}
\hline \multirow[t]{2}{*}{ Target } & \multirow{2}{*}{$\begin{array}{l}\text { Impact } \\
\text { velocity } \\
v_{\mathrm{i}}[\mathrm{m} / \mathrm{s}]\end{array}$} & \multicolumn{2}{|c|}{$\begin{array}{l}\text { Residual velocity } \mathrm{v}_{\mathrm{r}} \\
{[\mathrm{m} / \mathrm{s}]}\end{array}$} & \multirow{2}{*}{$\begin{array}{c}\text { Relative } \\
\text { difference } \\
{[\%]}\end{array}$} \\
\hline & & Measured & Predicted & \\
\hline \multirow{3}{*}{$\mathrm{K} / \mathrm{L}-9$} & 334.37 & 280.1 & 315.96 & 12.8 \\
\hline & 400 & 352.5 & 384.5 & 9.1 \\
\hline & 493 & 4555.5 & 4880.8 & 6.02 \\
\hline \multirow{3}{*}{$\mathrm{K} / \mathrm{L}-6$} & 310 & 263.8 & 296.5 & 12.39 \\
\hline & 342 & 298.85 & 329.9 & 10.39 \\
\hline & 393 & 354.5 & 382.2 & $\overline{77.8}$ \\
\hline \multirow{3}{*}{$\mathrm{K} / \mathrm{L}-3$} & 259.4 & 240 & 251.1 & $\overline{4} 4.62$ \\
\hline & 305.5 & 288.9 & 298.4 & 3.28 \\
\hline & 436.2 & 422 & 431.3 & 2.2 \\
\hline
\end{tabular}

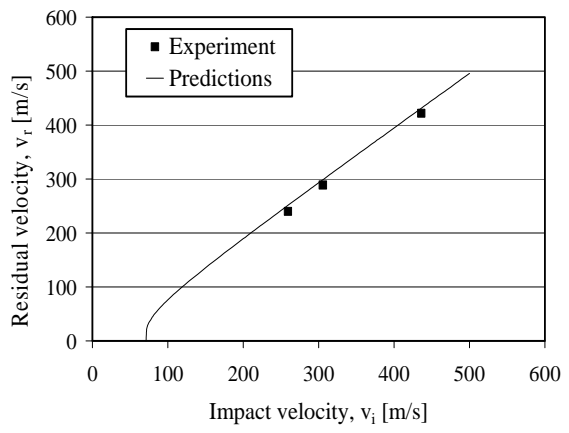

Fig. (24) Comparison between predicted and measured residual velocities for K/L-3 target

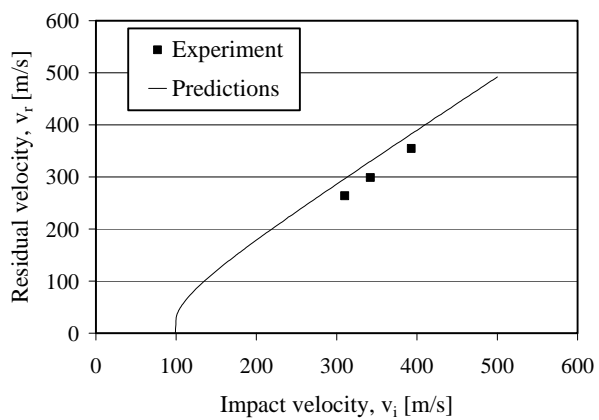

Fig. (25) Comparison between predicted and measured residual velocities for K/L-6 target

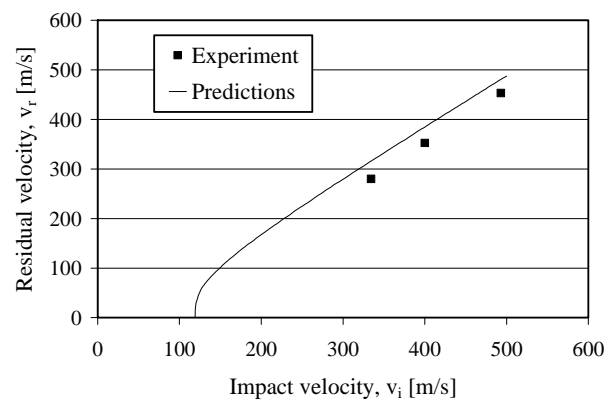

Fig. (26) Comparison between predicted and measured residual velocities for K/L-9 target

Figure (27) shows the relation between the number of target layers and the predicted ballistic limit for the Kevlar and composite targets. This curve helps to find out suitable target configuration to resist certain velocity in the range of 150 $\mathrm{m} / \mathrm{s}$.

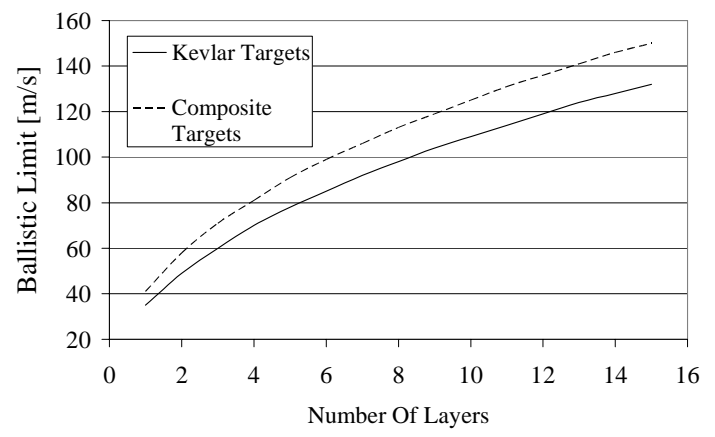

Fig. (27) Predicted ballistic limit for different Kevlar and composite targets

\section{Post Firing Examinations}




\section{For Kevlar targets}

Figures (28) and (29) show photographs of the front and back face of six-layer and nine-layer Kevlar targets. The failure mode of these targets is tensile failure. The yarns of the textile were subjected to high strain during projectile penetration and stretched to failure. The figures show also that the damage was not localized. The formed bulge after penetration was rhombus. This agrees with Leech, et al [1].The area which affected by the plastic deformation in case of the nine-layer target was smaller than that of the six-layer target. This indicates that adding more layers to the target gives the target additional resistance rather than fiber tension. In other words, the rear layers back-up the front ones.

\section{For composite targets}

Figure (30) and (31) show photographs of front and back face of six-layer and nine-layer composite targets. The failure mode of these targets is the same as that of the Kevlar targets, it is, tensile failure. This can be noticed from the exit hole of the projectile; no plugging to the target material can be found after firing. The damaged area of the composite targets are rather localized. This may be attributed to the flexibility presented to the fabric by adding the LINE-X layer to it.

\section{CONCLUSIONS}

Motion of the target material is successfully analyzed by using Newtonian formulation in which the both displacement and the strain are calculated.

- The maximum relative difference between the measured and predicted residual velocities in the case of Kevlar targets did not exceed $2.96 \%$ in the range of impact velocities of (250-420) m/s

- In the case of composite targets, the relative difference amounted to $12.8 \%$ at most in the same range of impact velocity.

- The model is more efficient in the case of Kevlar textile and needs some modification to enhance its predictive capabilities in the case of composite.

- The specific energy absorbed by a composite target is always higher than that absorbed by the equivalent Kevlar target. In the case of mean impact velocity of $402 \mathrm{~m} / \mathrm{s}$, the average absorbed energy per one layer for Kevlar targets is $6.43 \mathrm{~J}$ for K-3, $6.71 \mathrm{~J}$ for K-6 and $6.86 \mathrm{~J}$ for K-9. Similarly, the average absorbed energy per one layer for composite targets at the same impact velocity is $15.8 \mathrm{~J}$ for $\mathrm{K} / \mathrm{L}-3,18.7 \mathrm{~J}$ for $\mathrm{K} / \mathrm{L}-6$ and $15.5 \mathrm{~J}$ for K/L-9.

- Energy absorbed by a target having certain number of Kevlar layers was almost doubled in the case of a composite target having the same number of Kevlar layers.

- The energy absorbed by K/L-3 target is nearly equal to that of $\mathrm{K}-6$ target, while the cost of a K/L-3 target is $55 \%$ of the cost of a K-6 target.

- Post-firing examination of composite targets show recoverable behavior and localized damage after the ballistic impact; this indicates less trauma effect in case of using this composite as body armor material.

- Post-firing examination of the Kevlar targets shows that the deformed area has a pyramid configuration, as considered in the present model. 


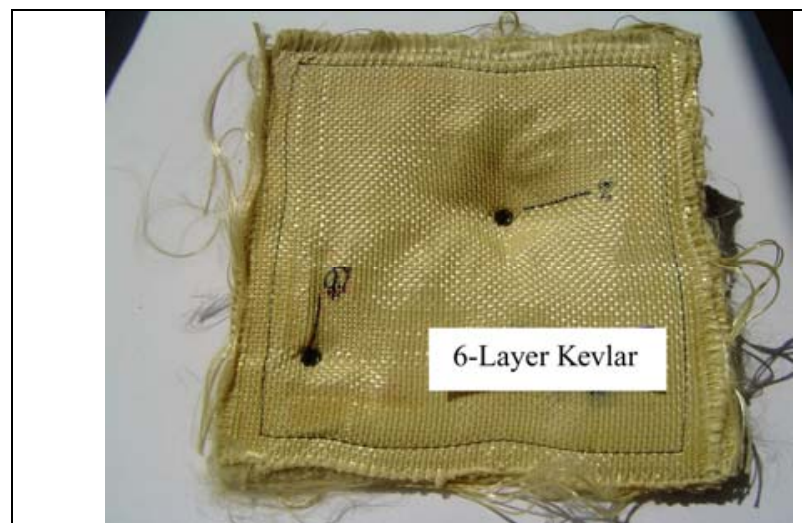

(a)

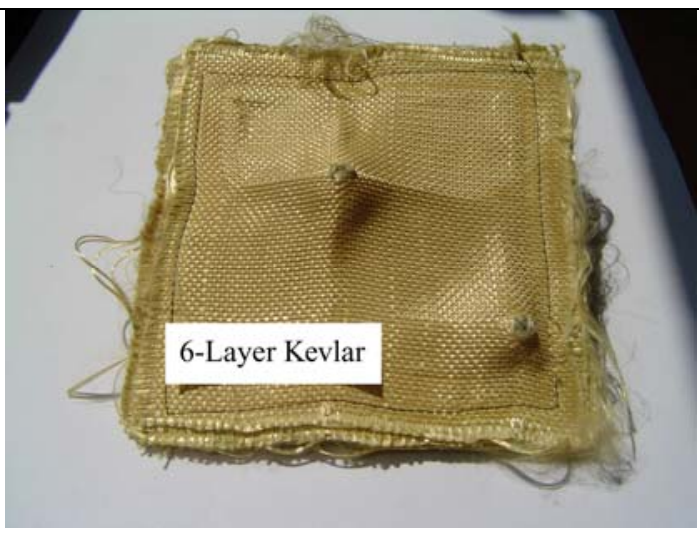

(b)

Fig (28) A K-6 target perforated by 7.62 projectiles with different velocities at normal impact: (a) front face, and (b) back face

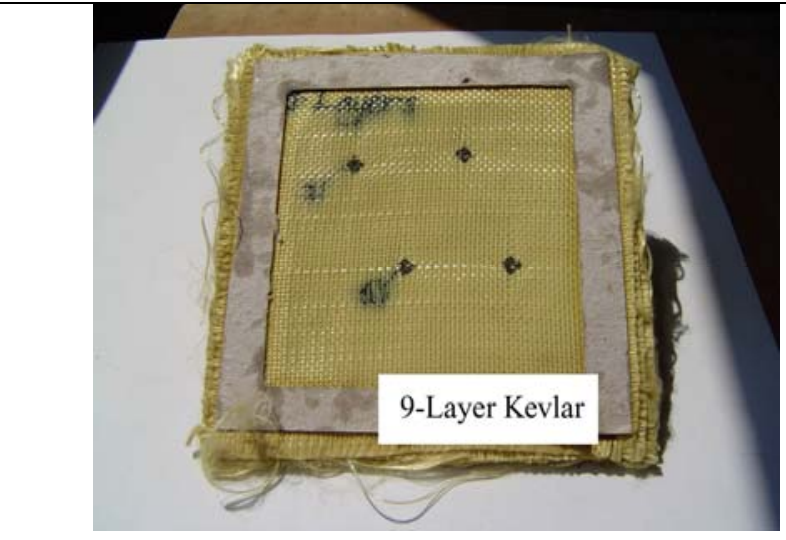

(a)

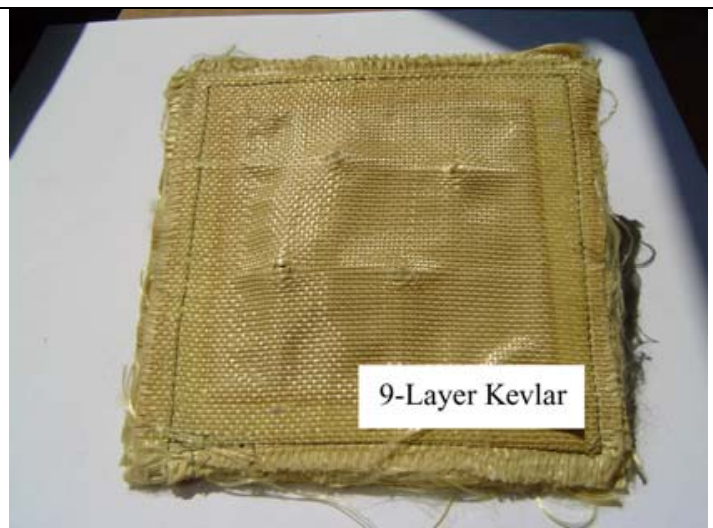

(b)

Fig (29) A K-9 target perforated by 7.62 projectiles with different velocities at normal impact: (a) front face, and (b) back face

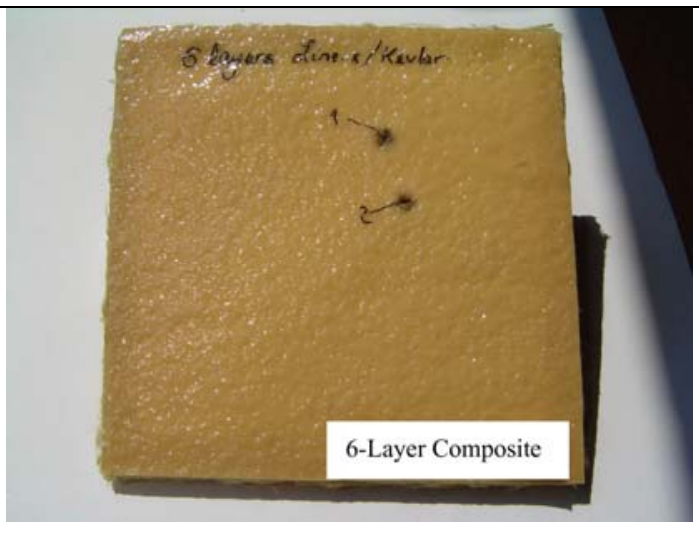

(a)

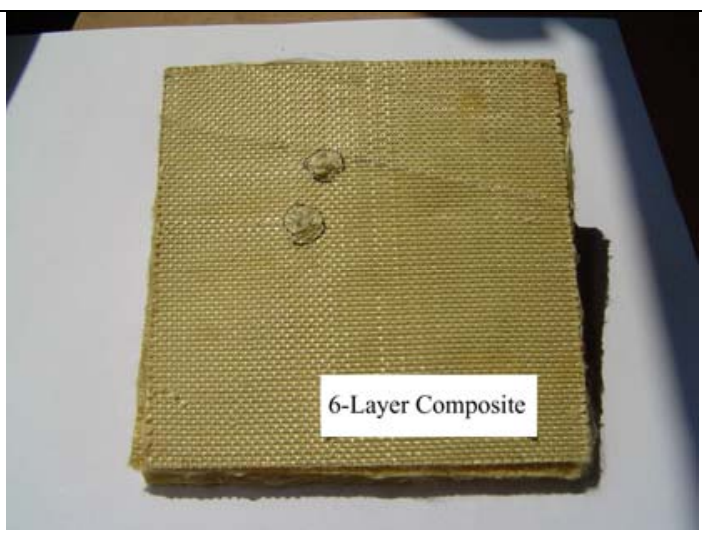

(b)

Fig. (30) A K/L-6 target perforated by 7.62 projectiles with different velocities at normal impact: (a) front face, and (b) back face 


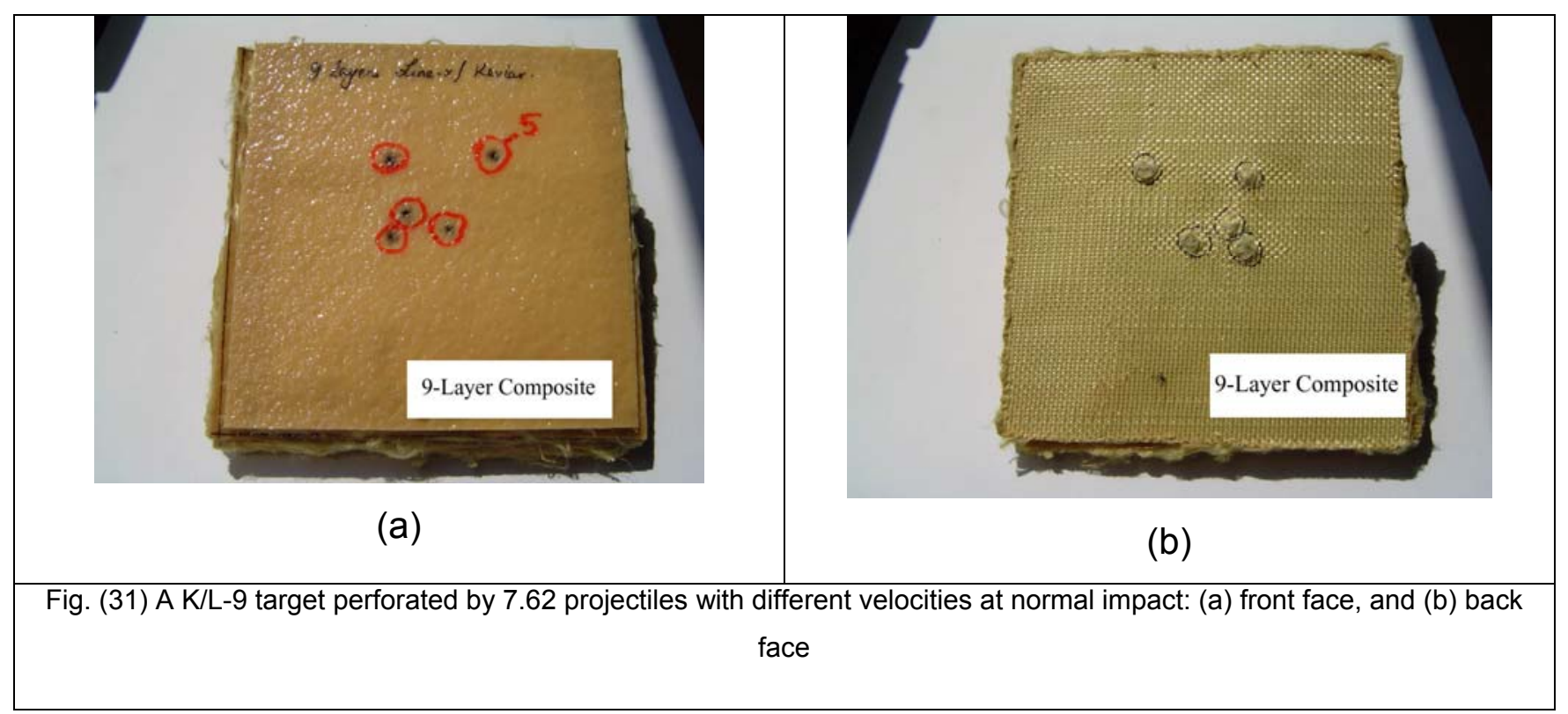

\section{REFERENCES}

1. C.M. Leech, J. W. S. Hearle, and J. Mansell, 'A Variational Model for the Arrest Projectiles by Woven Cloth and Nets', J. of Textile Institute, No.11, pp. 469-478, (1979).

2. G. Zhu, W. Goldsmith, and C.K.H. Dharan, 'Penetration of Laminated Kevlar by Projectiles-II. Theoritical investigation', Int. J. Solid Structures, Vol. 29, No. 4, pp. 421-436, (1992).

3. V.P.W. Shim, C.T. Lim, and K.J. Foo, 'Dynamic Mechanical Properties of Fabric Armor' Int. J. of Impact Engng., vol. 25, pp. 1-15, (2000).

4. James D. Walker, 'Ballistic Limit of Fabrics with Resin', $19^{\text {th }}$ Int. Symp. on Ballistics, vol. 3, pp. 442-453, USA, (2001).

5. E. DeLuca, j. Prifti, W. Betheney and S. C. Chou, 'Ballistic Impact Damage of S2-Glass-Reinforced Plastic Structural Armor', Composite Science Technology, vol 58, pp. 1453-1462, (1998).

6. H. H. Billon, and D. J. Robinson, 'Models for the Ballistic Impact of Fabric Armor', Int. J. of Impact Engng., vol. 25, pp. 411-422, (2001).

7. Fayed A., Leech C. M., 'Theoretical Investigation of the Performance of Flexible Composite Targets Against Ballistic Impact', ASME-ESDA2000, Montreux, Switzerland, July, (2000).

8. A. I. Fayed, A. M. Raid, and S. A. Salah, 'Perforation of a Small Caliber Projectile into Textile/Epoxy Composite Targets', $10^{\text {th }}$ International Conf. 
on Aerospace Science \& Aviation Technology, Proc. $10^{\text {th }}$ ASAT Conf, M. T. C., Cairo, 13-15 May, (2003).

9. A. Fayed, E. Elawad, and M. S. Abdelkader, 'Ballistic Resistance of Flexible Composite (KEVLAR-129/LINE-X xs 350)', 11 ${ }^{\text {th }}$ International Conf. on Aerospace Science \& Aviation Technology, Proc. $11^{\text {th }}$ ASAT Conf, M. T. C., Cairo, 17-19 May, (2005).

10.A. D. Resnyansky and G. Kataselis, 'Penetration Equations for Normal and Oblique Impact of Small Arms Projectiles Against Carbon-Fiber Composite', $21^{\text {st }}$ Int. Symp. of Ballistics, pp. 1411-1423, Sidney, (2004).

11. Abdel-Kader M. S., 'Effect of Projectile Impact Velocity and Target Thickness on Penetration Resistance of Mild Steel', Proc. $4^{\text {th }}$ ASAT Conf., M.T.C., Cairo, 14-16 May, (1991).

12. Almohandes A. A., Abdel-Kader M. S., and Eleiche A. M., 'Ballistic Performance of Single and Laminated Mild Steel Plates', Proc. AMME-6 Conf., M.T.C., Cairo, 3-5 May,(1994).

13. Bohong Gu, 'Analytical Modeling for the Ballistic Perforation of Plannar Plain-Woven Fabric Target by Projectile,' Composites: Part B 34, pp.361371, (2003).

14.D. Roylance and S. S. Wang, 'Penetration Mechanics of Textile Structures', in 'Ballistic Materials and Penetration Mechanics', Roy C. Laible, Elsevier, pp. 273-292 (1980). 